\title{
Ectopic cyclin D1 overexpression increases chemosensitivity but not cell proliferation in multiple myeloma
}

\author{
YOSHIAKI KURODA ${ }^{1}$, AKIRA SAKAI $^{1}$, NAOHIRO TSUYAMA ${ }^{2}$, YUTA KATAYAMA ${ }^{3}$, SHOSO MUNEMASA ${ }^{1}$, \\ HIDEKI ASAOKU ${ }^{3}$, YOSHIKO OKIKAWA ${ }^{1}$, NANAE NAKAJU ${ }^{1}$, MAMI MIZUNO ${ }^{4}$, KATSUNARI OGAWA ${ }^{5}$, \\ TAKASHI NISHISAKA $^{6}$, HIROTAKA MATSUI ${ }^{7}$, HIDEO TANAKA $^{1}$ and AKIRO KIMURA ${ }^{1}$ \\ ${ }^{1}$ Department of Hematology and Oncology, RIRBM, ${ }^{2}$ Department of Analysis Molecular Medicine, Hiroshima University; \\ ${ }^{3}$ Department of Internal Medicine, Hiroshima Red-Cross Hospital; Departments of ${ }^{4}$ Blood Transfusion Service, \\ ${ }^{5}$ Clinical Pathology, Hiroshima University Hospital; ${ }^{6}$ Department of Pathology and Laboratory Medicine, \\ Hiroshima Prefectural Hospital; ${ }^{7}$ Division of Molecular Oncology, RIRBM, Hiroshima University, Hiroshima, Japan
}

Received June 20, 2008; Accepted August 19, 2008

\section{DOI: 10.3892/ijo_00000110}

\begin{abstract}
We established a myeloma cell line (RPMI8226) with cyclin D1 overexpression in which the transfected cyclin D1 gene was stably expressed. D1 transfectants showed down-regulation of cyclin D2. Cell proliferation analysis did not show any differences among RPMI8226, mock control, and D1 transfectants. The number of S-phase cells increased while the number of $G_{0} / G_{1}-$ and $G_{2} / M$-phase cells decreased in D1 transfectants, which indicates a prolonged S-phase caused by cyclin $\mathrm{D} 1$ transfection. A decreased number of $\mathrm{G}_{2} / \mathrm{M}$-phase cells was also detected in myeloma cells of patients with translocation $\mathrm{t}(11 ; 14)(\mathrm{q} 13 ; \mathrm{q} 32)$. Western blot analysis revealed an increase in the hyperphosphorylated form of retinoblastoma $(\mathrm{Rb})$ protein in $\mathrm{D} 1$ transfectants; however, the expression of p53, p16, Bax, Bad, Bcl-2, and Mcl-1 did not significantly change. Treatment with anti-myeloma drugs (melphalan, dexamethasone, bortezomib and immunomodulatory compounds) induced apoptosis earlier in D1 transfectants compared with RPMI8226 and mock control via the activation of both caspase- 8 and -9 . However, we could not detect a relationship between cyclin D1 expression and the response to treatment with VAD and bortezomib. Therefore, we assume that high sensitivity to anti-myeloma drugs depends on the duration of the S-phase, but a clinical response might depend on the number of myeloma cells with cyclin D1 overexpression.
\end{abstract}

\section{Introduction}

Multiple myeloma (MM) is an incurable plasma cell dyscrasia whose mechanism of oncogenesis is still unclear. Reciprocal

Correspondence to: Dr Akira Sakai, Department of Hematology and Oncology, RIRBM, Hiroshima University, 1-2-3 Kasumi, Minami-ku, Hiroshima 734-8553, Japan

E-mail: sakira@hiroshima-u.ac.jp

Key words: multiple myeloma, cyclin D1, cyclin D2, cell cycle, chemosensitivity chromosomal translocations between the $\operatorname{IgH}$ gene located on chromosome 14q32, and other chromosomal partners that are supposed to be candidate oncogenes, such as cyclin D1 located on chromosome 11q23, arise in myeloma cells during isotype switching. On the other hand, the oncogenetic activity of cyclin D1 is needed in cooperation with myc genes in the generation of B-cell lymphoma in transgenic mice (1). Cyclin D1 is normally not expressed in plasma cells. Cyclin D dysregulation is reported to be recognized in about half of patients with MM (2-5). In particular, cyclin D1 expression associated with $\mathrm{t}(11 ; 14)(\mathrm{q} 13 ; \mathrm{q} 32)$ was detected in about 15-20\% of MM, whereas cyclin D1 expression without chromosomal translocation was detected in $37 \%$ of MM (6), which contained either a polysomy of chromosome 11 or no abnormality of chromosome 11. Cyclin D1 is a D-type cyclin that plays a key role in cell cycle regulation during the $G_{1}$ - to S-phase transition by binding to cyclin-dependent kinase 4 (CDK4) and CDK6, resulting in phosphorylation and inactivation of the retinoblastoma protein $(\mathrm{RB})$. Therefore, various neoplasia showing high expression of cyclin D1 have been supposed to be in a phase of proliferation, indicating that cyclin D1 overexpression could be a marker of poor prognosis.

Recent reports revealed that MM patients with cyclin D1 overexpression showed long survival and good response to treatment (7-9). Furthermore, according to a study by Zhan et al among 7 groups of MM patients identified using cDNA microarray analysis (10), two showed high expression of cyclin D1 together with low expression of cyclin D2. These were in the low-risk group. On the other hand, the group showing high expression of cyclin D2 belonged to the highrisk group. Previously, we reported that cyclin D2 was downregulated in myeloma cells with cyclin D1 overexpression; therefore, the expression of cyclin D1 and D2 could be inversely associated (11). Furthermore, we revealed that myeloma cells with cyclin D1 overexpression are not always positive for Ki67 (11).

Thus, we assumed that the expression of cyclin D1 could be an important feature to characterize myeloma cells. Here, we established a myeloma cell line showing cyclin D1 over- 
expression by transfecting the cDNA of the cyclin D1 gene into RPMI8226, which does not express cyclin D1, and we subsequently investigated the difference in response to antimyeloma agents in RPMI8226 cell lines with and without cyclin D1 overexpression. Furthermore, we investigated the response to chemotherapy, VAD, or bortezomib plus dexamethasone, according to the expression of cyclin D1 in MM patients.

\section{Materials and methods}

Reagents. Bortezomib (PS-341) and the immunomodulatory compounds (CC-4047, CC-6032, CC-5013, or lenalidomide) were kind gifts from Millennium Pharmaceuticals Inc. (Cambridge, MA, USA) and Celgene Corporation (Warren, NJ, USA), respectively. They were dissolved in dimethylsulfoxide (DMSO) and stored at $-20^{\circ} \mathrm{C}$. The final concentration of DMSO in all experiments was $<0.1 \%$. Dexamethasone sodium phosphate (Dexa) was a gift from Merck and Co. Inc. (Rahway, NJ, USA) and dissolved in $\mathrm{H}_{2} \mathrm{O}$ (stock concentration of $10 \mathrm{mM}$ ). Melphalan (Sigma-Aldrich, St. Louis, MO, USA) was dissolved in ethanol plus 3 drops of $<10 \%$ hydrochloric acid (stock concentration $50 \mathrm{mg} / \mathrm{ml}$ ). General caspase inhibitor (Z-VAD-FMK) was obtained from R\&D Systems Inc. (Minneapolis, MN, USA).

Cell lines. Jeko-1 (Mantle cell lymphoma) (12), which overexpresses cyclin D1 and has a Bcl-1/JH gene rearrangement, was a gift from Dr T. Akagi (Department of Pathology, Okayama University, Japan). U266, in which cyclin D1 overexpression is caused by the insertion of excised $\operatorname{IgH}$ switch sequences on chromosome 11q13 (13), was a gift from Dr H. Ishikawa (Department of Immunohematology, Yamaguchi University, Japan). KMS12BM, KMS21BM, and KMS11 were gifts from Dr T. Otsuki (Department of Hygiene, Kawasaki Medical School, Japan). KMS12BM and KMS21BM show cyclin D1 overexpression due to chromosomal translocation $\mathrm{t}(11 ; 14)(\mathrm{q} 13 ; \mathrm{q} 32)$, and KMS 11 has chromosomal translocation $\mathrm{t}(4 ; 14)$ (q16.3;q32.3).

Establishment of cyclin D1 transfected myeloma cells. RPMI8226 human MM cells were obtained from American Type Culture Collection (Rockville, MD, USA) and maintained in RPMI-1640 medium (Nissui, Tokyo, Japan) supplemented with $10 \%$ fetal bovine serum (Biological Industries, Israel). Plasmid pUHD10-3 containing the full-length cDNA corresponding to human cyclin D1 (14) was a gift from Dr S.I. Reed (The Scripps Research Institute, La Jolla, CA, USA). A $1.1-\mathrm{kb}$ fragment containing the full-length cDNA was removed by digestion with BamHI. Subseqently, this fragment was ligated into the pQCXIP Retroviral Vector (Clontech Laboratories Inc., Palo Alto, CA, USA). Vectors containing the cyclin D1 gene or empty vectors were transfected into RPMI8226 using the Retro- $X^{\text {Tм }}$ System (Clontech Laboratories) according to the manufacturer's instructions. Clones were selected by limiting dilution in the presence of $1 \mu \mathrm{g} / \mathrm{ml}$ puromycin and were analyzed for the expression of cyclin D1. We established three clones (S9-3, S3-3, S3-4) expressing cyclin D1 constitutively and a mock transfection control clone transfected with empty vector (called Vector). Transfectant cells (S9-3, Vector) were maintained in RPMI-1640 medium with $10 \% \mathrm{FCS}$ in the presence of $1 \mu \mathrm{g} / \mathrm{ml}$ puromycin. We used the S9-3 clone for studies of cyclin D1 overexpressing myeloma cells.

cDNA synthesis from myeloma (plasma) cell purification. Bone marrow (BM) mononuclear cells (MNCs) were as described previously (15). Written informed consent was obtained from all patients. Total RNA was isolated using an RNasy Mini Kit (Qiagen, Valencia, CA, USA) from plasma cells purified (>95\%) using MACS CD138 Micro Beads (Miltenyi Biotec, Auburn, CA, USA) according to the manufacturer's instructions. First-strand cDNA was made as described previously $(11,16)$.

Competitive RT-PCR to analyze the expression of cyclin D1, $D 2$, and D3. RT-PCR was performed according to the methods described by Uchimaru et al (17), and was performed previously by Katayama et al (11).

Immunohistochemistry (IHC) to detect cyclin D1 expression. After centrifuging three cell lines (RPMI8226, Vector, S9-3) in Eppendorf tubes, the cell clots were embedded in paraffin to make sections. IHC was performed according to the labeled streptavidin-biotin method using a mouse monoclonal antibody directed against human cyclin D (NCL-Cyclin D1GM; clone P2D11F11) (Vision Biosystems Ltd., Mount Waverley, Australia).

Western blot analysis. Cells were lysed (1\% Nonidet P-40, $150 \mathrm{mmol} / \mathrm{l} \mathrm{NaCl}$, and $0.1 \%$ sodium deoxycholate in $20 \mathrm{mmol} / \mathrm{l}$ Tris, $\mathrm{pH}$ 7.5) in the presence of a protease inhibitor cocktail (Sigma-Aldrich). After $30 \mathrm{~min}$ on ice, lysates were centrifuged at $14,000 \mathrm{rpm}$ for $30 \mathrm{~min}$ at $4^{\circ} \mathrm{C}$ and supernatants collected. Each $50 \mu \mathrm{g}$ of protein was separated by $10 \%$ or $15 \%$ SDS polyacrylamide gel electrophoresis and transferred to a nitrocellulose membrane, immunoblotted with the indicated antibodies, and visualized using enhanced chemiluminescence (ECL) Western blotting detection reagents (Amersham Pharmacia Biotech). For Western blot analysis of cytochrome $\mathrm{c}$ in the cytosol fraction, cells were lysed [10 $\mu \mathrm{g} / \mathrm{ml}$ digitonin, $110 \mathrm{mM} \mathrm{CH}_{3} \mathrm{COOK}, 5 \mathrm{mM} \mathrm{CH}_{3} \mathrm{COONa}, 2 \mathrm{mM}$ $\left(\mathrm{CH}_{3} \mathrm{COO}\right)_{2} \mathrm{Mg}, 1 \mathrm{mM}$ EGTA, $2 \mathrm{mM}$ DTT in $20 \mathrm{mM}$ HEPES, $\mathrm{pH} 7.5$ ] in the presence of a protease inhibitor cocktail (Sigma). After incubation for $5 \mathrm{~min}$ at $37^{\circ} \mathrm{C}$, lysates were centrifuged at $14,000 \mathrm{rpm}$ for $15 \mathrm{~min}$ at $4^{\circ} \mathrm{C}$. Supernatants were collected for the cytosolic fraction, and pellets were used for the mitochondrial fraction. The primary antibodies included anticyclin D1, anti-cyclin D2, anti-MCL-1, anti-RB, anti-PARP, anti-caspase-8, anti-caspase-9 (BD Pharmingen ${ }^{\mathrm{TM}}$, San Diego, CA, USA), anti-Bcl-2, anti-Kip1/p27 (BD Transduction Laboratories), anti-Bad, anti-Bax, anti-p16, anti-CDK4 (Santa Cruz Biotechnology, Santa Cruz, CA, USA), anti-p53, antiphospho-p53 (S15) (R\&D Systems), anti-cytochrome c (BioVision, Mountain View, CA, USA), and anti-GAPDH (HyTest Ltd., Turku, Finland).

Cell proliferation assay. For the cell proliferation assay, Cell Counting Kit-8 (called 'WST-8 assay' in this paper) (Dojindo Laboratories, Kumamoto, Japan) was used according to the 
manufacturer's instructions. This assay is based on colorimetric quantification of NADH (18). To analyze the doubling time of cell proliferation, cells were suspended in Roswell Park Memorial Institute (RPMI)-1649 medium (Nissui) supplemented with $10 \%$ fetal calf serum (FCS; M.A. Bioproducts, Walkersville, MD, USA), and seeded at $1.0 \times 10^{5} / \mathrm{ml}$, in a final volume of $100 \mu 1$ (10\% FCS) in 96-well flat-bottom plates (Corning, NY, USA) in triplicate. Plates were incubated at $37^{\circ} \mathrm{C}$ in a $5 \% \mathrm{CO}_{2}$ incubator for 1 to 3 days. At the end of the incubation, $10 \mu \mathrm{l}$ of WST-8 reagent was added to each well and the plates were incubated for $4 \mathrm{~h}$. Absorbance was then measured using an ImmunoMini NJ-2300 plate reader (Nalge Nunc International, Rochester, NY, USA). Cell viability was determined by staining with a 1:1 mixture of trypan blue stain $0.4 \%$ (Gibco-BRL) and cells.

Cell cycle analysis and detection of cells in S-phase. For each culture condition, $5 \times 10^{5}$ cells were prepared by using a Cycle Test $^{\text {TM }}$ Plus DNA Reagent Kit (BD Biosciences, San Diego, CA, USA), according to the manufacturer's instructions, and analyzed with a FACScalibur (BD Biosciences) with data analyzed by CellQuest sp2 and ModFit LT software (BD Pharmingen $^{\mathrm{TM}}$ ). For the detection of cells entering and progressing through S-phase, $1 \times 10^{6}$ cells (RPMI8226, Vector, S9-3) were labeled by incubation with bromodeoxyuridine (BrdU) for $8 \mathrm{~h}$ and subsequently fixed and stained using a BrdU Flow Kit (BD Biosciences) according to the manufacturer's instructions, and analyzed with a FACS calibur (BD Biosciences).

Real-time quantitative RT-PCR (RQ-PCR). The expression of cyclin D1, D2, and D3 was analyzed on an ABI PRISM 7700 Sequence detector (Perkin-Elmer/Applied Biosystems). Primers and probes: cyclin D1, 5'-TGGAGGTCTGCGAGG AACAG-3' and 5'-CCTTCATCTTACAGGCCACGAA-3'; TaqMan probe for cyclin D1, 5'-FAM-TGGCCATGAACTA CCT-MGB-3'; cyclin D2, 5'-GTGAGGAACAGAAGTGCG AAGAA-3' and 5'-TTTGGAGGCCAGGAACATG-3'; TaqMan probe for cycln D2, 5'-FAM-TACCTGGACCGTTT CT-MGB-3'; cyclin D3, 5'-GCCCTCTGTGCTACAGATTA TACCTT-3' and 5'-CACTGCAGCCCCAATGCT-3'; TaqMan probe for cyclin D3, 5'-FAM-CCCGCCATCCATGAT-MGB$3^{\prime}$. The primers and probe for GAPDH were designed by Applied Biosystems.

Fluorescence in situ hybridization (FISH) analysis. FISH analysis was performed at the Center for Molecular Biology and Cytogenetics, SRL, Inc. (Hachioji, Tokyo, Japan). The target for FISH analysis was a cell with a round nucleus. The LSI IGH/CCND1 dual color (Abbott Molecular Inc., Des Plaines, IL, USA), dual fusion DNA probe, which hybridizes to chromosome 14q32.3 (IgH SpectrumGreen) and chromosome 11q13 (CCND1 SpectrumOrange), was used to detect the translocation of $\mathrm{t}(11 ; 14)(\mathrm{q} 13 ; \mathrm{q} 32.3)$.

Detection of apoptosis. RPMI8226, Vector, and S9-3 were treated with bortezomib, dexamethasone, melphalan, and immunomodulatory compounds for the appropriate time for each. Cells were stained with Annexin V-FITC and propidium iodide (PI) using a MEBCYTO ${ }^{\circledR}$ apoptosis kit (MBL, Nagoya, Japan) and analyzed by flow cytometry.
Relationship between cyclin D1 expression and treatment response or cyclin D2 expression. We investigated the relationship between cyclin D1 expression and treatment response in 22 myeloma patients. Patient characteristics are shown in Table I. The median age was 64 years (range 51-74), with 13 males and 9 females. The clinical stage was determined according to the staging system of Durie and Salmon (19). Expression of cyclin D1, D2, and D3 was analyzed by RQPCR before treatment with VAD or bortezomib. Response to treatment was evaluated according to the International Uniform Response Criteria for multiple myeloma (20). We also analyzed the relationship between cyclin D1 and D2 expression in 158 MM patients.

Statistical analysis. Statistical analysis of the experimental data was performed using Dunnett's test. Significant differences were inferred when $\mathrm{p}<0.05(*)$ or $\mathrm{p}<0.01(* *)$. Statistical analysis of clinical data in myeloma patients was performed using Pearson correlations and t-tests.

\section{Results}

Establishment of RPMI8226 derivative showing strong cyclin D1 expression. FISH analysis did not detect $\mathrm{t}(11 ; 14)$ (q13;q32) in RPMI8226, but it did show the possibility of chromosome 11q aneuploidy in the cell line (data not shown). We also confirmed that the expression of cyclin D1 was not detected in RPMI8226 by competitive RT-PCR, Western blotting, and immunohistochemical (IHC) staining (Fig. 1). We chose RPMI8226 as the parent cell line, and subsequently transfected full-length cyclin D1 cDNA using a retroviral vector to establish clones expressing cyclin D1 stably. After limiting dilution, we picked up three clones (S3-3, S3-4, and S9-3) to screen cyclin D1 expression by RQ-PCR. We also established a mock control by transfecting an empty vector into RPMI8226 (called Vector). We confirmed cyclin D1 overexpression in the three transfection clones and no cyclin D1 expression in RPMI8226 or the mock control (Fig. 1A). The expression of cyclin D1 was also confirmed by competitive RT-PCR, Western blotting, and IHC staining (Fig. 1B-D). We analyzed how cyclin D1 overexpression affects the characteristics of myeloma cells using the cyclin D1 transfectant clone S9-3 and Vector as a control.

Cyclin D1 overexpression did not induce cell proliferation. Considering the role of cyclin D1 in promoting cell cycle progression, we expected that cyclin D1 transfection could induce high proliferation activity in myeloma cells. Here we used two methods to analyze cell growth. The cell proliferation curves of RPMI8226, Vector, and S9-3 showed a similar pattern in both trypan blue staining and WST-8 assays (Fig. 2). Therefore, cyclin D1 overexpression in RPMI8226 did not induce a growth advantage.

Cyclin D1 overexpression increased cell numbers in S-phase. Cyclin D1 represents a critical determinant of $G_{1} / S$ progression in the cell cycle $(21,22)$. We investigated whether cyclin D1 transfection would promote $\mathrm{G}_{1} / \mathrm{S}$ progression. Cell cycle analysis revealed that cyclin D1 transfectants (S9-3) showed a significant $(\mathrm{p}<0.01)$ increase in cell numbers in the $\mathrm{S}$-phase compared with those of RPMI8226 and Vector $(67.1 \%, 41.8 \%$, 


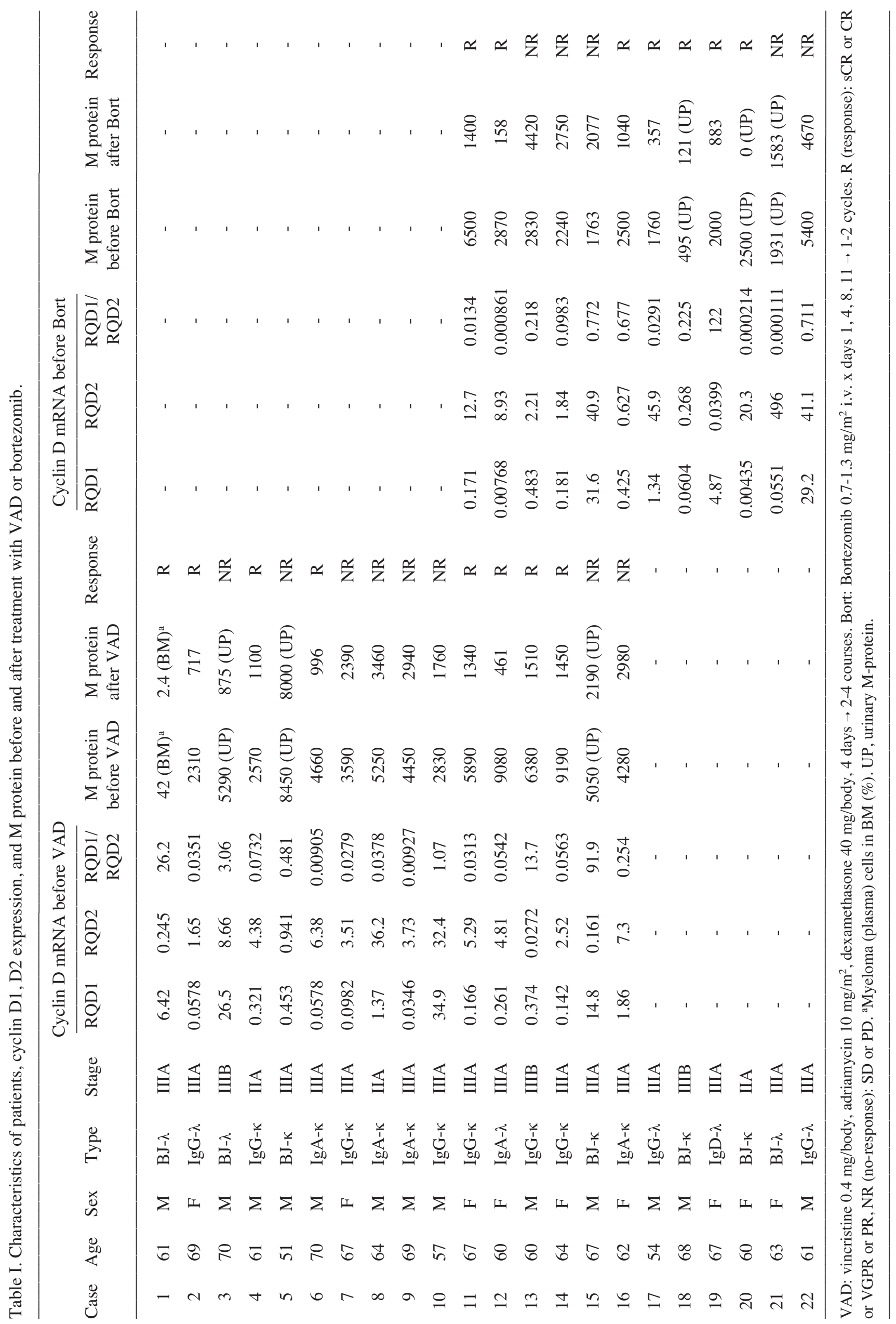


(A)

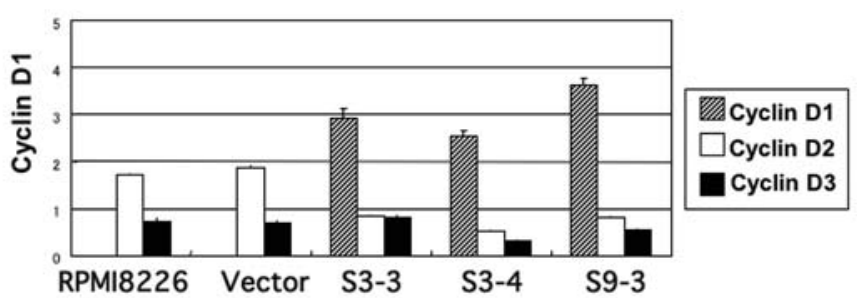

(D)

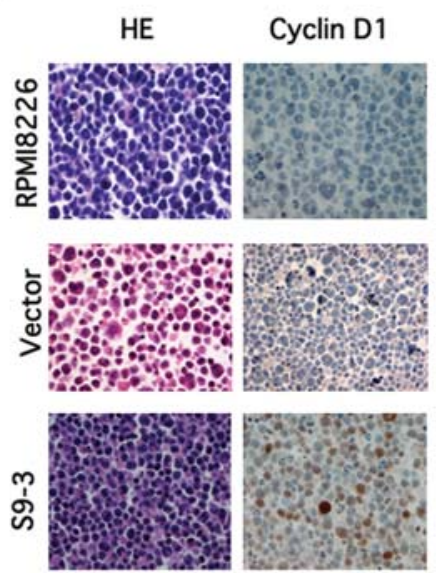

(B)

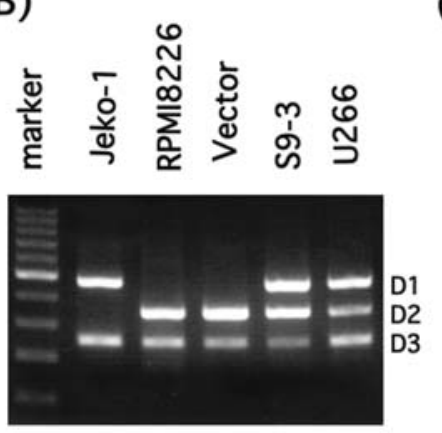

(C)

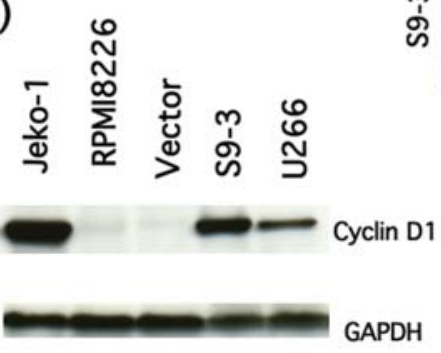

Figure 1. Detection of cyclin D1 expression in the cyclin D1 transfectant. (A), We picked three clones (S3-3, S3-4, S9-3) after limiting dilution, and screened for cyclin D1 expression by RQ-PCR. Subsequently, we chose S9-3 as the cyclin D1 transfectant. (B), Competitive RT-PCR analysis. (C), Western blotting and (D), Immunohistochemical staining revealed that S9-3 expressed cyclin D1 intensively. Jeko-1 is a mantle cell lymphoma cell line with cyclin D1 overexpression caused by Bcl1/JH rearrangement. U266 is a myeloma cell line with cyclin D1 overexpression caused by the insertion of excised IgH switch sequences on chromosome $11 \mathrm{q} 13$. Vector is the mock transfection control.

(A)

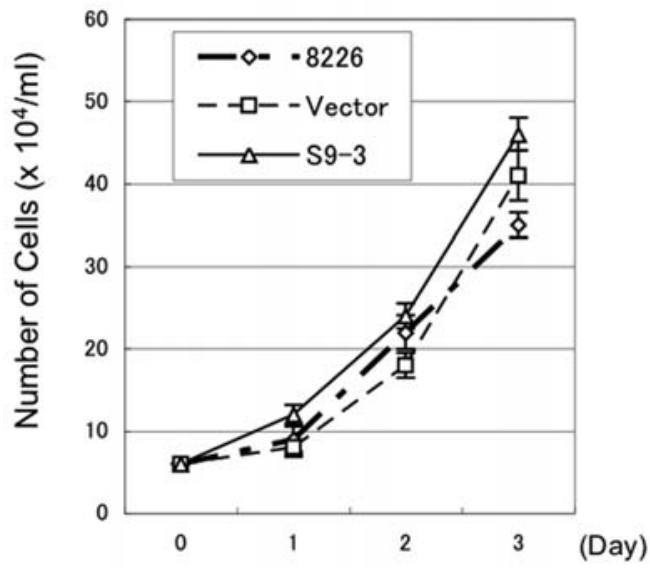

(B)

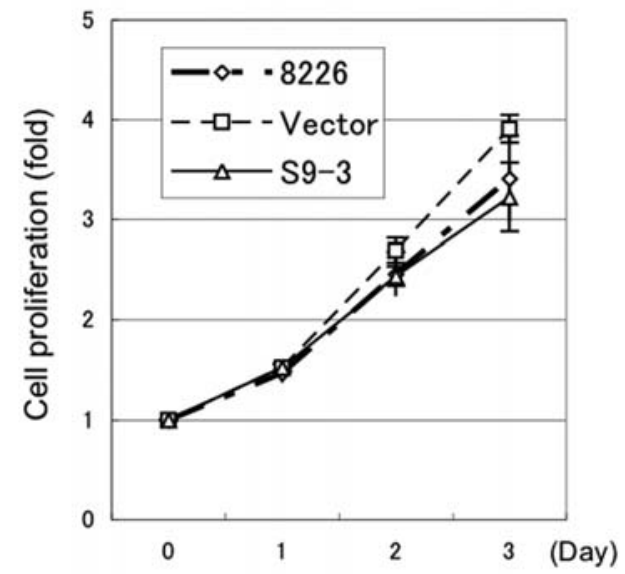

Figure 2. Effect of cyclin D1 expression on cell growth. RPMI8226, Vector, and S9-3 were cultured, and (A), Cells were counted by trypan blue staining and (B), Cell proliferation was measured by WST-8 assay every day for 3 days. Results are mean \pm SD of 3 independent experiments.

and $35.7 \%$, respectively) (Fig. 3A). On the other hand, cell numbers in the $\mathrm{G}_{0} / \mathrm{G}_{1}$-phase showed a significant $(\mathrm{p}<0.01)$ decrease, which was inversely correlated with the S-phase. Cell numbers in the $\mathrm{G}_{2} / \mathrm{M}$-phase significantly $(\mathrm{p}<0.01)$ decreased rather than increased in S9-3. These results indicated that cyclin D1 overexpression increased cell numbers in the S-phase but that these cells did not progress to the $\mathrm{G}_{2} / \mathrm{M}$-phase, and that cell numbers of $\mathrm{S} 9-3$ in the sub- $\mathrm{G}_{1^{-}}$ phase (apoptotic cells) did not increase compared with those of RPMI8226 and Vector. Therefore, cyclin D1 overexpression per se did not seem to induce apoptosis in RPMI8226. Furthermore, we analyzed active DNA synthesis, in which cells enter and progress through the S-phase, by immunofluorescent staining of incorporated BrdU. We incubated myeloma cells with BrdU for $8 \mathrm{~h}$ because labeling time less than $4 \mathrm{~h}$ was not enough to detect myeloma cells in the S-phase 
(A)

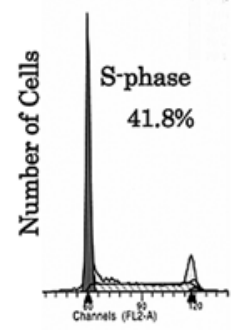

RPMI8226

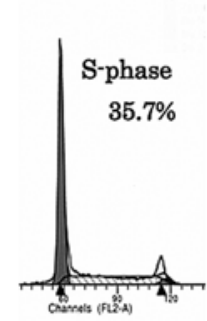

Vector

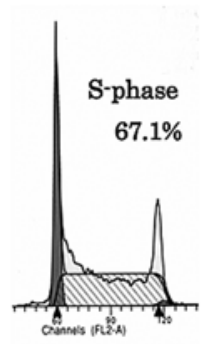

S9-3
(B)

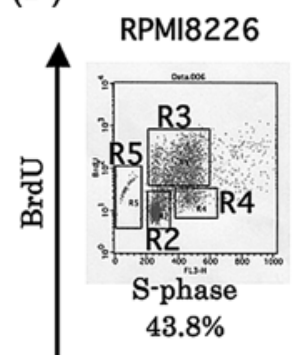

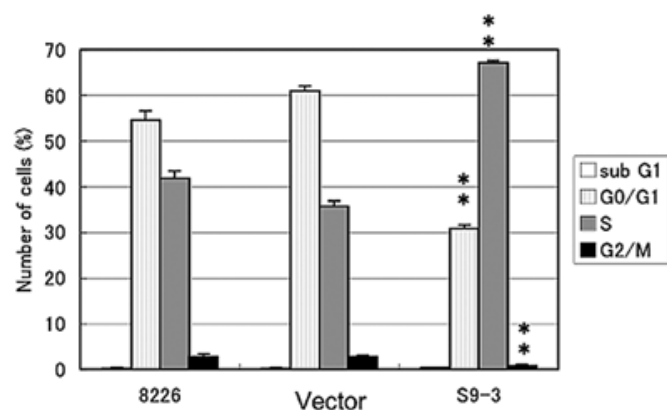

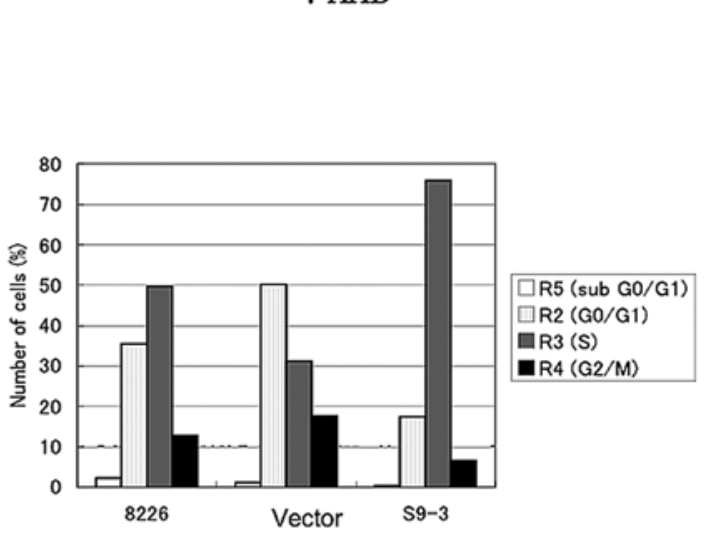

(C) Case 1

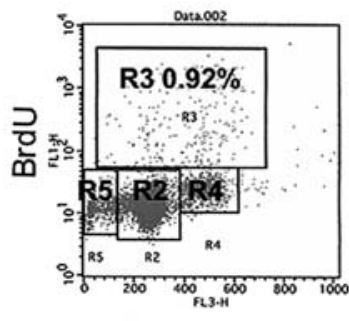

$-1$

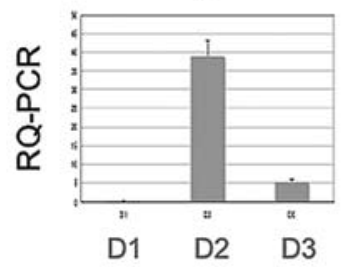

FISH $\quad 13 q-, t(4 ; 14)$
Case 2

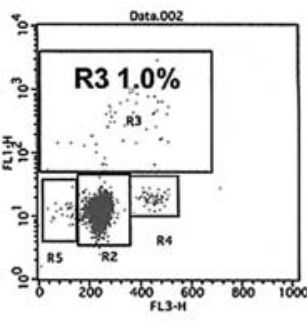

sat

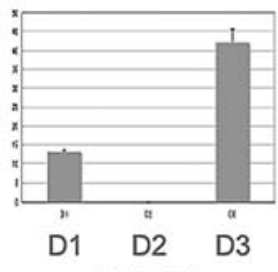

$t(11 ; 14)$
Case 4

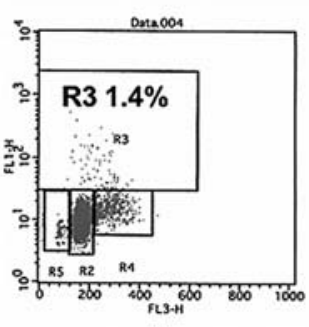

cot

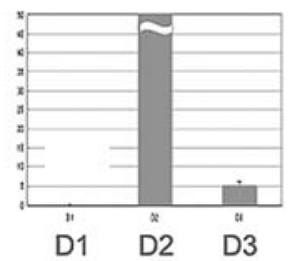

S9-3

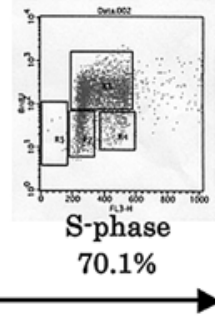

7-AAD

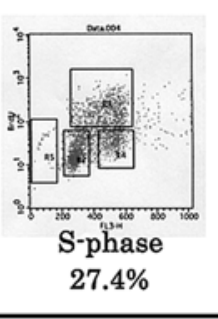

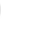

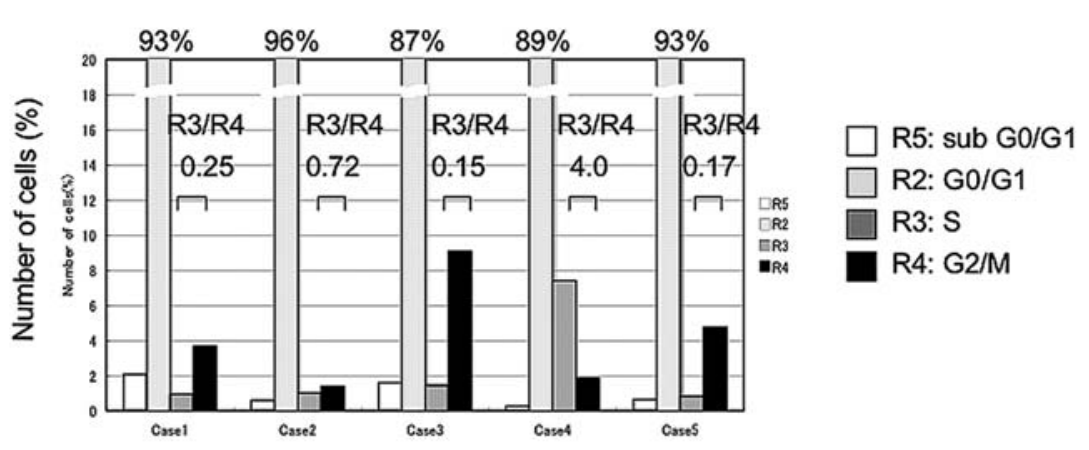

Figure 3. Effect of cyclin D1 overexpression on cell cycle progression. (A), Cell cycle analysis using a Cycle TEST ${ }^{\mathrm{TM}}$ PLUS DNA Reagent Kit. Numbers indicate the percentage of cells in S-phase. Percent of cells in sub- $\mathrm{G}_{0} / \mathrm{G}_{1^{-}}, \mathrm{G}_{0} / \mathrm{G}_{1^{-}}, \mathrm{S}-$ - or $\mathrm{G}_{2} / \mathrm{M}$-phases is indicated in the lower graph. Results are mean $\pm \mathrm{SD}$ of 3 independent experiments. ${ }^{* *}$ Significant difference ( $\left.\mathrm{p}<0.01\right)$ compared with RPMI8226 and Vector. (B), Analysis of cell numbers in S-phase using the BrdU Flow Kit. Measurement of cell-incorporated BrdU (with FITC anti-BrdU) and total DNA content (with 7-ADD). Incubation time for BrdU incorporation was 8 h. Numbers indicate the percentage of BrdU-positive cells. Percentage of cells in sub- $\mathrm{G}_{0} / \mathrm{G}_{1^{-}}, \mathrm{G}_{0} / \mathrm{G}_{1^{-}}, \mathrm{S}-$, or $\mathrm{G}_{2} / \mathrm{M}$-phases is indicated in the lower graph. R2, $\mathrm{G}_{0} / \mathrm{G}_{1^{-}}$ phase; R3, S-phase; R4, $\mathrm{G}_{2}+$ M-phase; R5, sub- $\mathrm{G}_{0} / \mathrm{G}_{1}$-phase. (C), Analysis of myeloma cells of patients using the BrdU Flow Kit as mentioned in (B) and

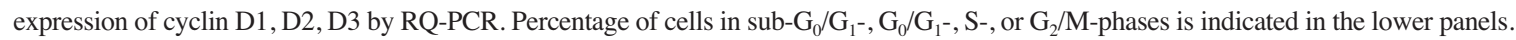


(A)

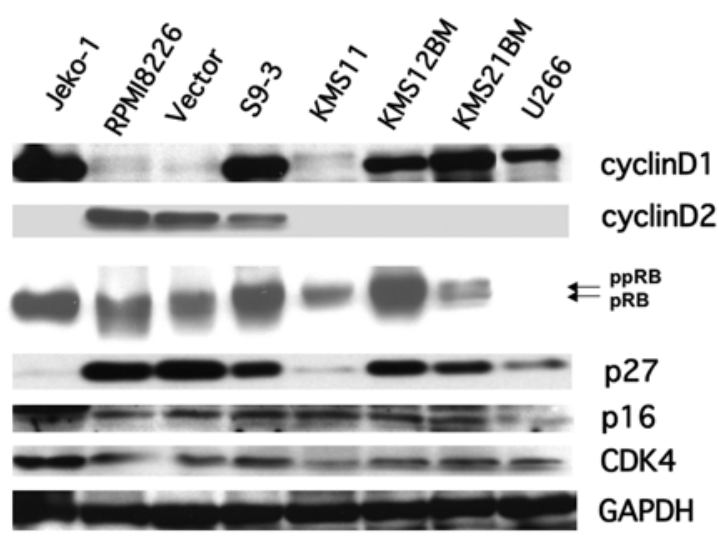

(C)

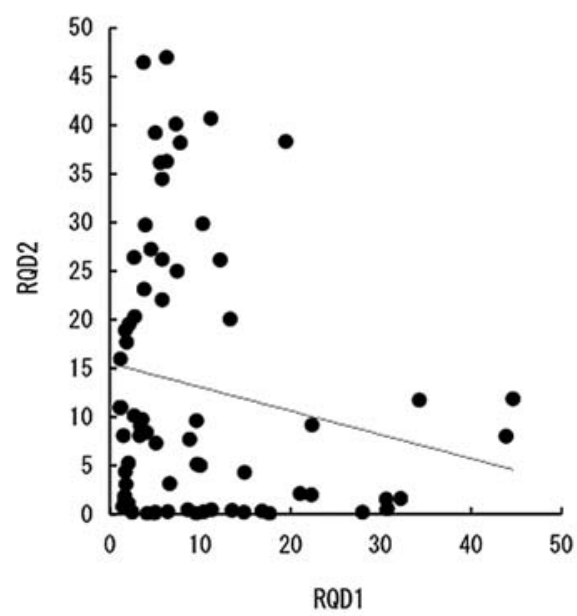

RQD1>1

$\mathrm{R}=-0.181$
(B)
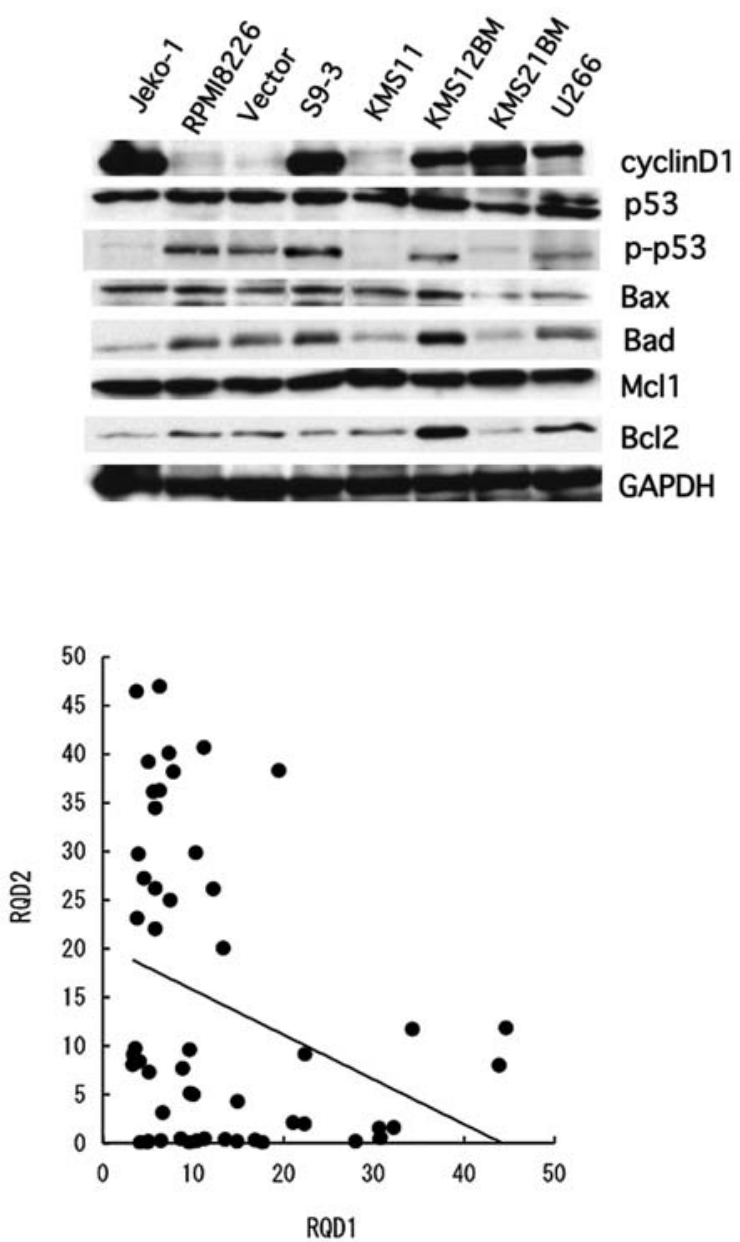

RQD1>3

$R=-0.324$

Figure 4. Relationship between cyclin D1 overexpression and expression of cell cycle or apoptosis-related proteins, and relationship between cyclin D1 expression and cyclin D2 expression in MM patients. (A), Lysates from Jeko-1, RPMI8226, Vector, S9-3, KMS11, KMS12BM, KMS21BM, and U266 were immunoblotted with anti-cyclin D1, cyclin D2, RB, p27, p16, CDK4, and GAPDH antibodies, and (B), with anti-cyclin D1, p53, phospho-p53 (S15, phosphorylated serine at position 15 of human p53), Bax, Bad, Mcl-1, Bcl-2, and GAPDH. Anti-GAPDH antibody was used to confirm equal loading of proteins. (C), Pearson correlation analysis shows the inverse relationship between cyclin D1 expression (RQD1: cyclin D1/GAPDH) and cyclin D2 expression (RQD2: cyclin D2/GAPDH) in MM patients with high expression of cyclin D1 ( $R=-0.181$ in $R Q D 1>1.0, R=-0.324$ in RQD1 >3.0).

especially in the myeloma cells of patients (data not shown). As shown in Fig. 3B, cells showing active DNA synthesis increased markedly in S9-3 compared with RPMI8226 and Vector, accompanied by a decrease of cell numbers in the $\mathrm{G}_{0} / \mathrm{G}_{1}$-phase and no increase in the $\mathrm{G}_{2} / \mathrm{M}$-phase, similar to the results from cell cycle analysis. Together with the result shown in Fig. 2, cyclin D1 overexpression increased cell numbers in the S-phase rather than promoting the cell cycle or cell proliferation. Therefore, cyclin D1 overexpression prolonged the duration of the S-phase.

Next, we analyzed myeloma cells of 5 patients by immunofluorescent staining of incorporated BrdU. Different from the analysis of three cell lines, cell numbers of the S-phase in $2 \mathrm{MM}$ patients (cases 2 and 4) with cyclin D1 expresion were not higher than those of the other three MM patients. The ratio of R3 (S-phase)/R4 $\left(\mathrm{G}_{2} / \mathrm{M}\right.$-phase) was higher in cases 2 and 4 compared with those of the other three cases (Fig. 3C). These two cases showed $47 \%$ and $95 \%$ chromosomal abnormality of $\mathrm{t}(11 ; 14)(\mathrm{q} 13 ; \mathrm{q} 32)$ in BM mononuclear cells by FISH analysis, respectively, and analysis by RQ-PCR revealed that they showed cyclin D1 expression without cyclin D2 expression. Therefore, myeloma cells with a high expression of cyclin D1 induced by $\mathrm{t}(11 ; 14)(\mathrm{q} 13 ; \mathrm{q} 32)$ might decrease cell numbers in the $\mathrm{G}_{2} / \mathrm{M}$-phase by a reduction of transition to the $\mathrm{S}$-phase.

Cyclin D1 overexpression increased expression of the hyperphosphorylated form of $R b(p p R b)$ and decreased cyclin $D 2$ and p27 expression in RPMI8226. Cyclin D1 is a key regulator of the transition from the $\mathrm{G}_{1}$ - to S-phase. $\mathrm{Rb}$ is hypophosphorylated and active in the $\mathrm{G}_{1}$-phase and becomes inactive through phosphorylation by CDK4 together with cyclin D1. As shown in Fig. 4, the cyclin D1 transfectant (S9-3) showed cyclin D1 overexpression and down-regulation of cyclin D2 compared with RPMI8226 and Vector. Of note, highly phosphorylated species of $\mathrm{Rb}$ (ppRb) increased in $\mathrm{S} 9-3$. 
(A)

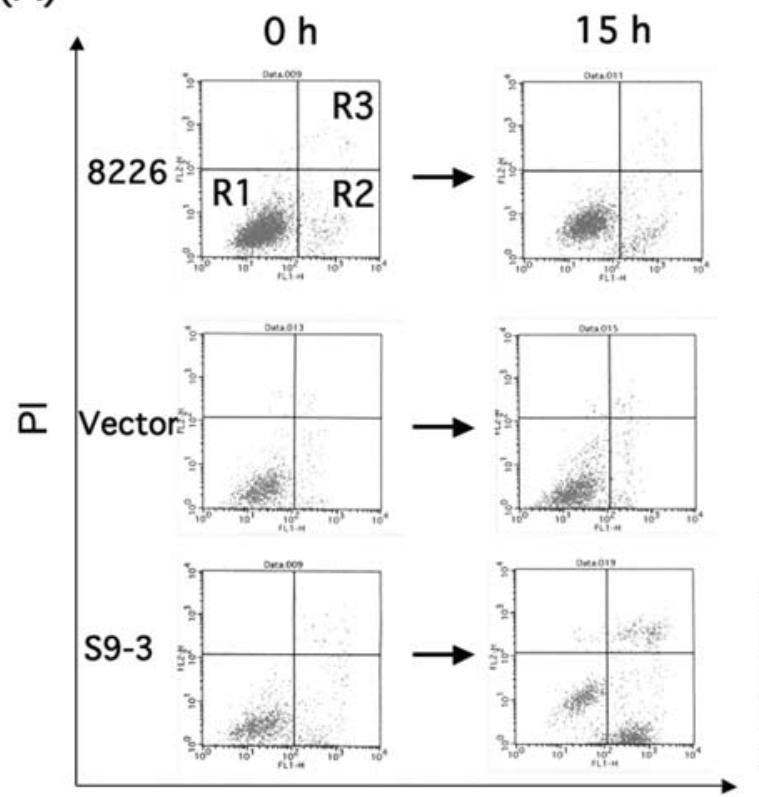

Annexin V

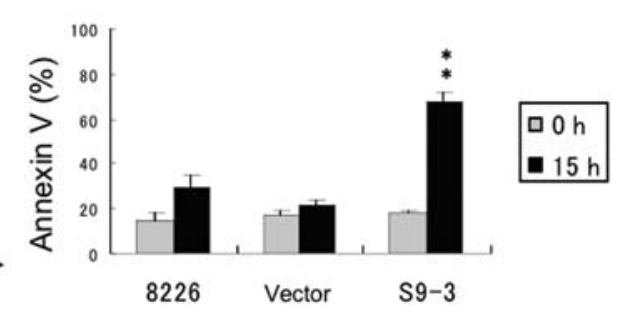

(B)

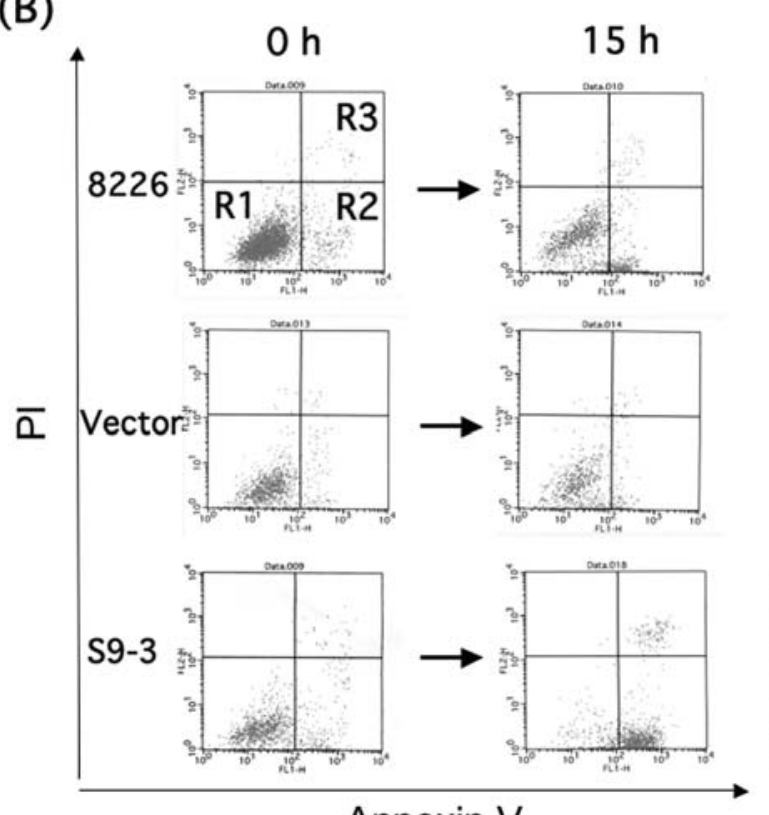

Annexin V

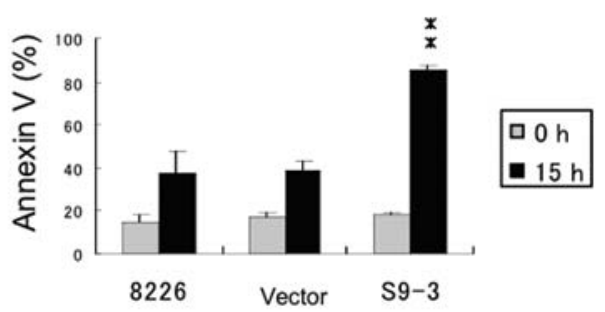

Contrary to our expectation that phosphorylation of Rb could be related to cyclin D1 expression, there was no expression of $\mathrm{Rb}$ in $\mathrm{U} 266$ because of the deletion of chromosome 13q14, in which the RB-1 gene is localized (23). The intensity of $\mathrm{pRb}$ expression in KMS21BM was similar to that in KMS11, in which cyclin D1 expression was not detected, while ppRb expression is increased in Jeko-1 and KMS12BM. Expression of CDK4, which binds with cyclin D1 to make a CDK4cyclin D1 complex, and its inhibitor, p16, did not change, but the expression of p27 decreased compared with that of RPMI8226 and Vector. Expressions of p53, phosphorylated p53 (S15), Bax, Bad, Mcl-1, and Bcl-2 in S9-3 were similar to those in RPMI8226 and Vector, and there were no specific changes in their expression in cell lines with cyclin D1 expression. Therefore, cyclin D1 overexpression in RPMI8226 resulted in remarkable down-regulation of cyclin D2 and $\mathrm{p} 27$, and an increase in the hyperphosphorylated form of $\mathrm{Rb}$ (ppRb).

Furthermore, in the analysis of myeloma cells of the patients, the Pearson correlation between cyclin D1 expression (RQD1; cyclin D1/GAPDH) and cyclin D2 expression (RQD2; cyclin D2/GAPDH) was 0.052, which indicated no relation between them (data not shown). However, focusing on myeloma patients with high expression of cyclin D1 (RQD1 >1.0, n=72), we found an inverse relationship of expression between cyclin D1 and D2 $(\mathrm{R}=-0.181)$ expression, especially in MM patients with RQD1 >3.0 (R=-0.324, n=52) (Fig. 4C). 
(C)

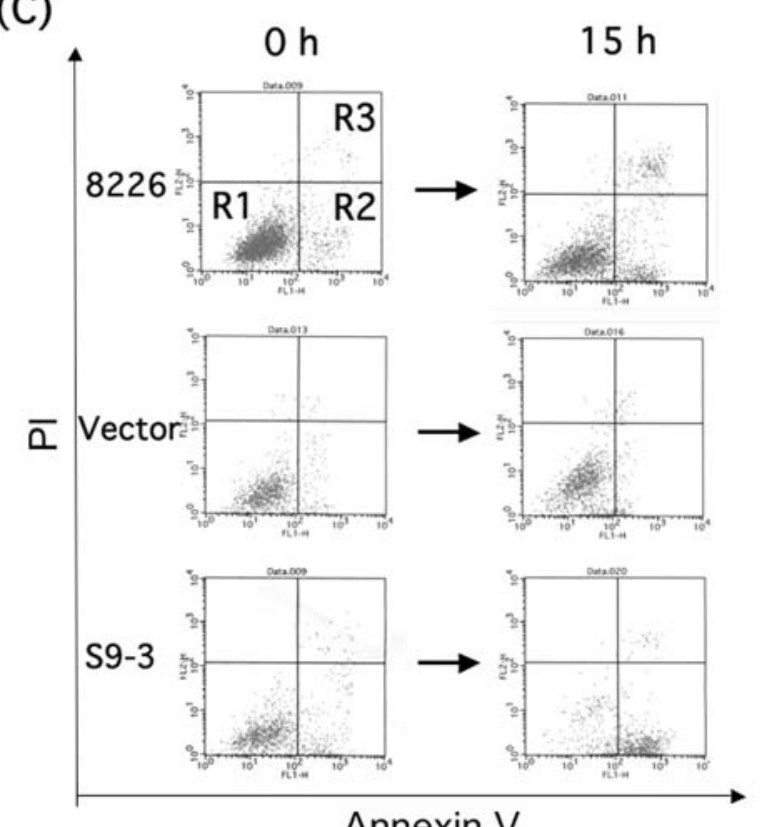

Annexin V
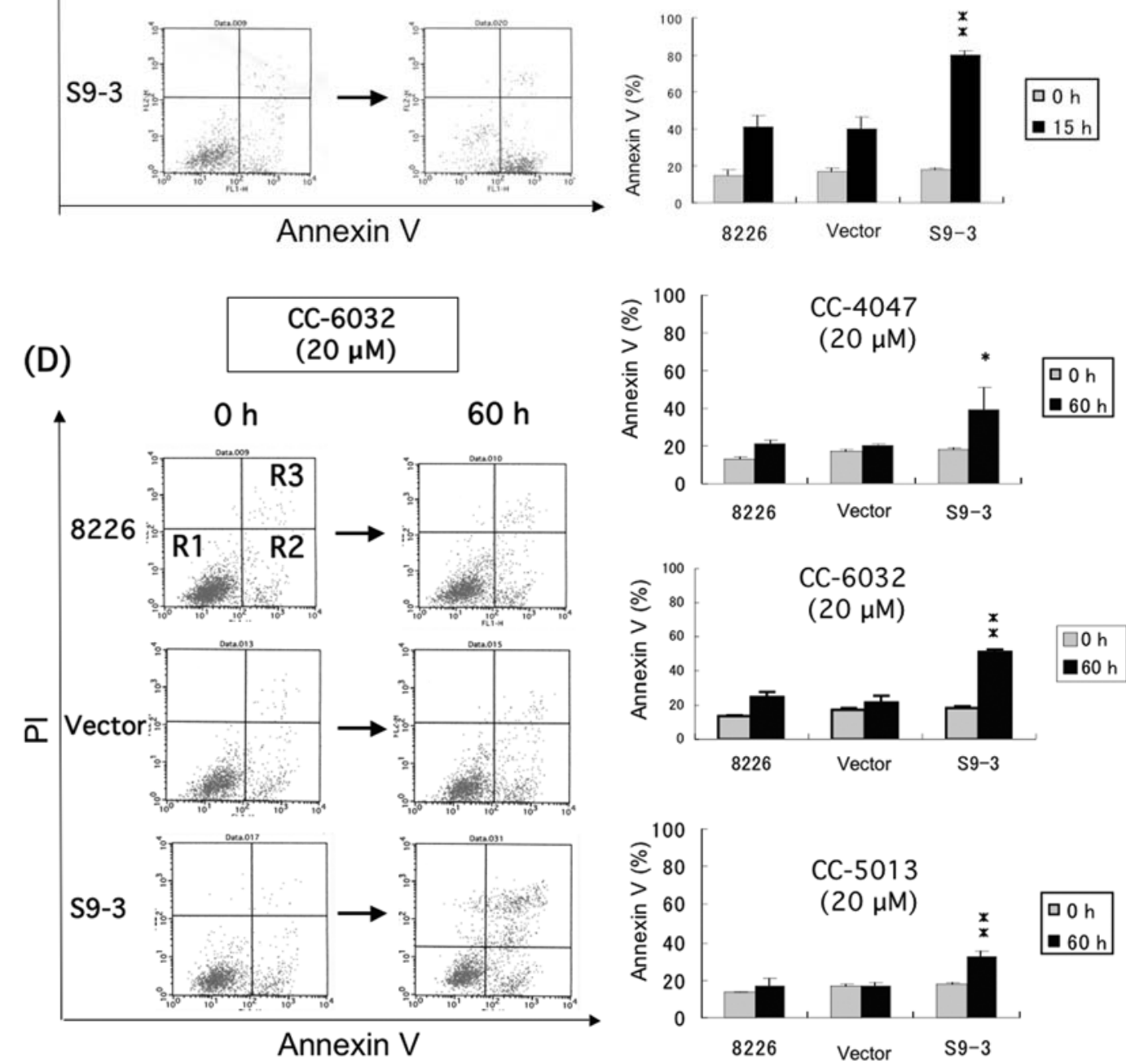

Figure 5. RPMI8226 overexpressing cyclin D1 became sensitized to dexamethasone, melphalan, bortezomib (PS341), and immunomodulatory compounds. (A), RPMI8226, Vector, and S9-3 were incubated with $20 \mu \mathrm{M}$ dexamethasone; (B), $10 \mu \mathrm{M}$ melphalan and (C), $20 \mathrm{nM}$ bortezomib for $15 \mathrm{~h}$, and (D), incubated with $20 \mu \mathrm{M}$ immunomodulatory compounds for $60 \mathrm{~h}$. The representative PI/Annexin V staining (left) and Annexin V-positive cell numbers (\%) (right) are presented. Results are mean \pm SD of 3 independent experiments. Significant differences $\left({ }^{* *} \mathrm{p}<0.01\right.$ and ${ }^{*} \mathrm{p}<0.05$, respectively) compared with RPMI8226 and XIP.

RPMI8226 with cyclin D1 overexpression was sensitized to dexamethasone, melphalan, bortezomib (PS341), and immunomodulatory thalidomide compounds. Considering that cyclin D1 overexpression is a favorable prognostic marker $(9,10)$, we expected that myeloma cells with cyclin D1 overexpression might be sensitive to the drugs used in chemotherapy for MM. We therefore investigated whether ectopic cyclin D1 overexpression would change the sensitivity of myeloma cells to dexamethasone, melphalan, bortezomib (PS-341), and the immunomodulatory compounds (CC-4047, CC-6032, CC-5013), which are representatives of the current chemotherapy for MM. In our preliminary study, we found no difference in the degree of apoptosis among these cell lines (RPMI8226, Vector, S9-3) in 30-h treatment with dexamethasone $(20 \mu \mathrm{M})$, melphalan $(10 \mu \mathrm{M})$, and bortezomib (PS-341) $(20 \mathrm{nM})$, or 15-h treatment with much higher 
(A)

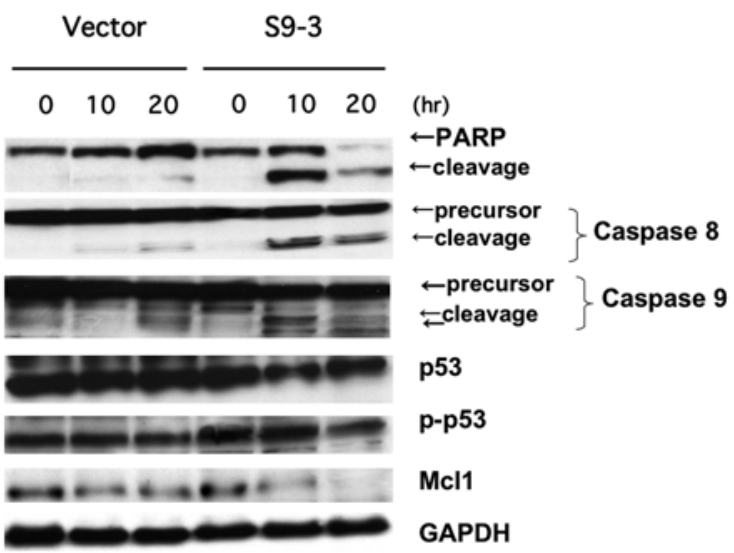

(c)

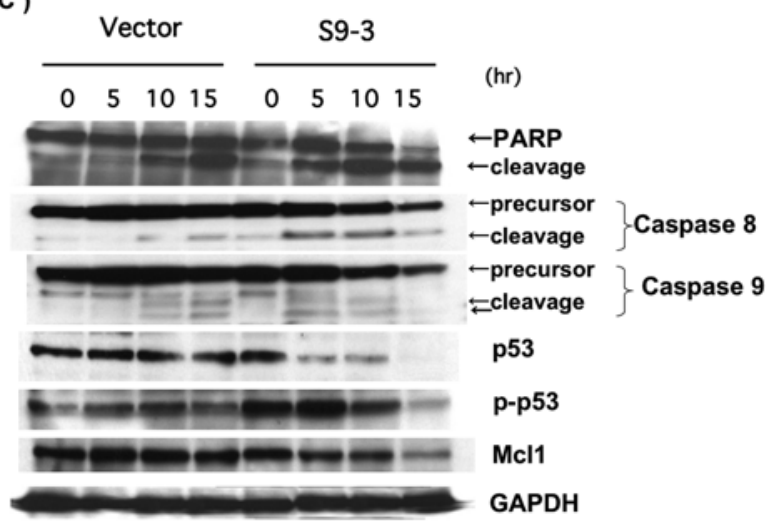

(B)

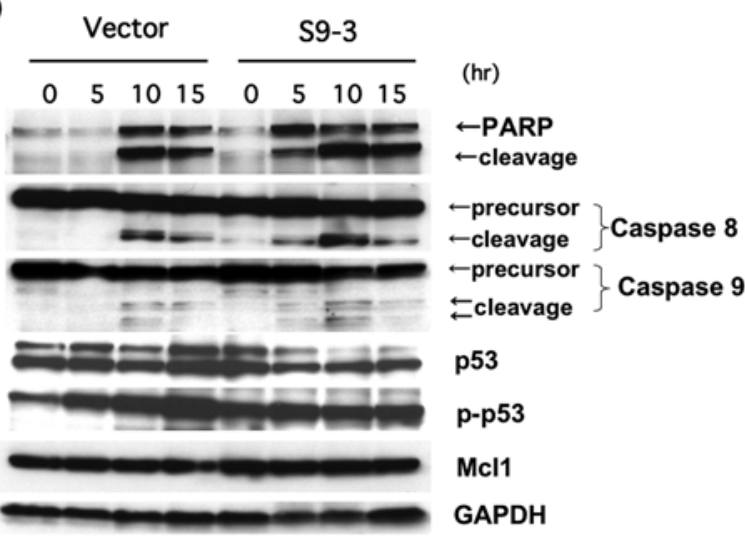

(D)

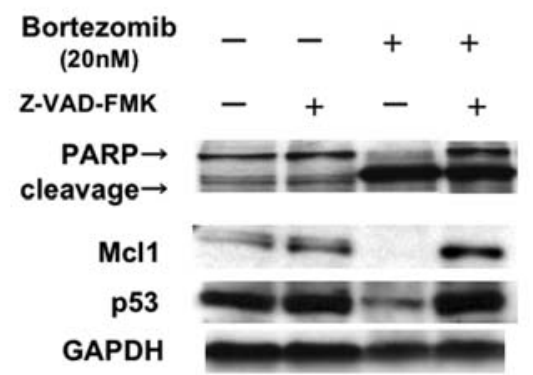

(E)

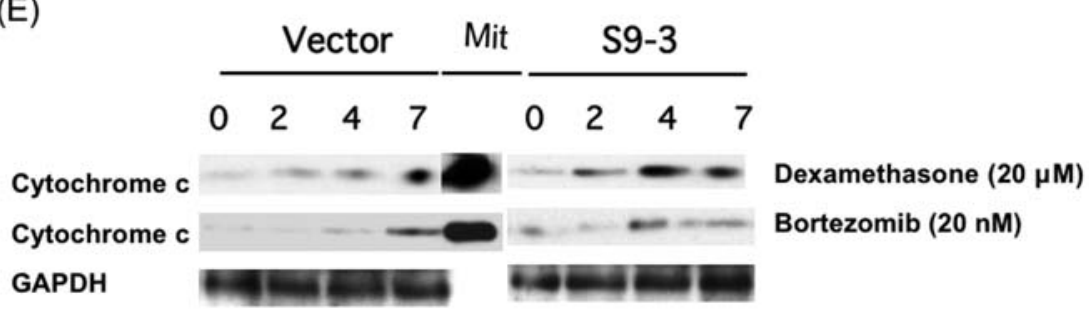

Figure 6. Expression of apoptosis-related proteins by treatment with dexamethasone, melphalan, and bortezomib (PS-341). (A), Lysates from Vector and S9-3 were immunoblotted with anti-PARP, caspase-8, -9, p53, phospho-p53 (S15, phosphorylated serine at position 15 of human p53), MCL-1, and GAPDH antibodies after treatment with $20 \mu \mathrm{M}$ dexamethasone up to $20 \mathrm{~h}$ and (B), $10 \mu \mathrm{M}$ melphalan or (C), $20 \mathrm{nM}$ bortezomib up to $15 \mathrm{~h}$. (D), Lysates from S9-3 were immunoblotted with anti-PARP, Mcl-1, p53, and GAPDH antibodies after treatment with or without $20 \mathrm{nM}$ bortezomib with $20 \mu \mathrm{M}$ pancaspase inhibitor (Z-VAD-FMK). (E), Cytosolic fractions of XIP and S9-3 were immunoblotted with anti-cytochrome c and GAPDH antibodies. Immunoblot using the mitochondrial fraction was a positive control. Anti-GAPDH antibody was used to confirm equal loading of proteins.

concentrations (data not shown) in the presence of $10 \%$ FBS. Cells were analyzed $15 \mathrm{~h}$ after treatment with these drugs in each of the above concentrations. As shown in Fig. 5A-C, the number of apoptotic cells in S9-3 was significantly $(\mathrm{p}<0.01)$ higher following treatment with dexamethasone, melphalan, and bortezomib. Therefore, these results suggested that myeloma cells with cyclin D1 overexpression might undergo apoptosis earlier following exposure to anti-myeloma drugs. On the other hand, the induction of apoptosis in these cells by the immunomodulatory compounds required more time (data not shown), and they were analyzed $60 \mathrm{~h}$ after the initiation of treatment. As shown in Fig. 5D, numbers of apoptotic cells in S9-3 were significantly higher when treated with these compounds ( $\mathrm{p}<0.05$ in $\mathrm{CC}-4047$, $\mathrm{p}<0.01$ in CC-6032 and CC-5013). These results suggested that myeloma cells with cyclin D1 overexpression could be more sensitive to antimyeloma drugs than myeloma cells without overexpression.
Early apoptosis induction in RPMI8226 with cyclin D1 overexpression by treatment with dexamethasone, melphalan, and bortezomib (PS-341). Considering that myeloma cells with cyclin D1 overexpression could be sensitive to antimyeloma drugs, we next tried to identify those that might induce apoptosis in S9-3. We treated the cells with dexamethasone $(20 \mu \mathrm{M})$, melphalan $(10 \mu \mathrm{M})$, and bortezomib $(20 \mathrm{nM})$ for up to $20 \mathrm{~h}$ in the presence of $10 \% \mathrm{FBS}$. We analyzed the expression of caspase- 8 and -9 in S9-3 and Vector by Western blotting to analyze which pathway, intrinsic or extrinsic, was involved in apoptosis. Apoptotic signals, such as DNA damage, induce cleavage of caspase- 8 and -9 . Poly(ADP-ribose) polymerase (PARP) is a target of the caspase protease activity associated with apoptosis, and PARP cleavage is also considered a marker of apoptosis. In the treatment with dexamethasone, cleaved forms of PARP, caspase-8, and -9 appeared earlier (at $10 \mathrm{~h}$ ) in S9-3 than in 
Table II. Relationship between cyclin D1 expression and response to treatment with VAD or bortezomib.

\begin{tabular}{lccc}
\hline & & $\begin{array}{c}\text { Change of M } \\
\text { protein (Pearson } \\
\text { correlations) } \\
\text { r-value }\end{array}$ & $\begin{array}{c}\text { Difference } \\
\text { between R and } \\
\text { NR (t-test) } \\
\text { p-value }\end{array}$ \\
\hline RQD1 (VAD) & 16 & 0.002 & 0.903 \\
RQD1 (Bort) & 12 & 0.379 & 0.185 \\
RQD1/RQD2 (VAD) & 16 & -0.093 & 0.508 \\
RQD1/RQD2 (Bort) & 12 & -0.095 & 0.345 \\
\hline
\end{tabular}

Abbreviations as in Table I.

Vector, and the expression of Mcl-1 gradually decreased in S9-3 (Fig. 6A). In the treatment with melphalan, cleaved forms of PARP, caspase-8, and -9 appeared at $5 \mathrm{~h}$ in S9-3, whereas these fragments appeared at $10 \mathrm{~h}$ in Vector. The decrease in the cleaved forms of caspase 8 and -9 at $15 \mathrm{~h}$ was thought to be due to proteolysis (Fig. 6B). In the treatment with bortezomib, the cleaved form of PARP was already increased by $5 \mathrm{~h}$ in S9-3, and fragments of caspase- 8 and -9 appeared at $5 \mathrm{~h}$ in S9-3, whereas these fragments appeared at $10 \mathrm{~h}$ in Vector. Decrease of the cleaved forms of caspase- 8 and -9 at $15 \mathrm{~h}$, and a decrease in the expression of $\mathrm{p} 53$ from $5 \mathrm{~h}$ and Mcl-1 at $15 \mathrm{~h}$ were also thought to be due to proteolysis by caspase-dependent cleavage (Fig. 6C). In fact, the decrease in PARP, p53, and Mcl-1 expression was reversed by treatment with pancaspase inhibitor (Z-VAD-FMK) (Fig. 6D). In particular, Mcl-1, an anti-apoptotic Bcl-2 family protein, is involved in the survival of myeloma cells (24-26). If these agents changed Mcl-1 expression, the decrease of Mcl-1 expression could occur as early as the cleavage of caspase- 9 . We did not find any significant difference in Bad, Bax, Bim, and Bcl-2 expression between in S9-3 and Vector (data not shown). Furthermore, we investigated cytochrome c release from mitochondria associated with dexamethasone and bortezomib treatment representatively because we found that caspase-9, a key component of the intrinsic pathway, was activated by the above three agents (Fig. 6E). Therefore, both pathways, intrinsic and extrinsic, were activated by treatment with dexamethasone, melphalan, and bortezomib irrespective of cyclin D1 overexpression; however, these activations were induced early in RPMI8226 with cyclin D1 overexpression. Immunomodulatory compounds also induced activation of both patways; however, we did not detect any significant differences in the activation of apoptotic signal molecules (caspase-8, -9, and PARP) between S9-3 and Vector (data not shown).

No correlation between high cyclin D1 expression and response to treatment with VAD or bortezomib. If cyclin D1 overexpression in myeloma cells could induce sensitivity to drugs such as dexamethasone and bortezomib, MM patients with high cyclin D1 expression would be expected to show a good response to treatment with VAD or bortezomib. First, we investigated the relationship between simple expression of cyclin D1 by RQ-PCR (RQD1) and the reduction of M-protein (or reduction of BM myeloma cells in case 1) or the response to treatment according to the International Uniform Response Criteria (20). However, we did not find any relationship between RQD1 and these outcomes following treatment with VAD or bortezomib (Table II). Next, we investigated whether a relatively high expression of cyclin D1 (RQD1/RQD2 >1) would be a favorable factor because MM patients with a high expression of cyclin D2 belonged to the high-risk group (10). However, we did not find any relationship between the ratio of RQD1/RQD2 and reduced M-protein or response to treatment (Table II). Therefore, we could not confirm that MM patients with high cyclin D1 expression would show a good response to chemotherapy.

\section{Discussion}

Whether cyclin D1 expression in myeloma cells is a favorable or unfavorable prognostic marker has long been controversial. Recently, Zhan et al revealed that MM patients with cyclin D1 expression belong to the group with favorable prognosis by molecular analysis (10). Cyclin D1 overexpression is associated with improved survival in breast cancer, and ectopic cyclin D1 overexpression in breast cancer cells induce apoptosis through the down-regulation of STAT3. Treatment with bortezomib amplifies this proapoptotic function by stabilizing the cyclin D1 protein (27).

To analyze the characteristics of myeloma cells with cyclin D1 overexpression, we established a myeloma cell line with cyclin D1 overexpression by transfecting the cDNA of the cyclin D1 gene via a retrovirus vector, and compared them with those of control cells transfected with the vector only. Although we tried to establish a cyclin D1-inducible system using the Tet-off system of Resnitzky et al (14), we could not establish a useful cyclin D1 transfected myeloma cell line because of low expression of cyclin D1 (data not shown). Sola and Troussard reported that RPMI8226 expresses cyclin D1 using Western blotting (28). However, we confirmed that RPMI8226 does not express cyclin D1 by competitive RT-PCR, Western blotting, IHC, and RQ-PCR (Fig. 1). Derivatives of RPMI8226 transfected with the cyclin D1 gene showed a similar intensity of cyclin D1 expression as those of KMS12BM, KMS21BM, and Jeko-1 (Fig. 4). As assumed in a previous study (11), the down-regulation of cyclin D2 might compensate for cyclin D1 overexpression; however, the reason why MM patients with high expression of cyclin D2 belong to the high-risk group (10) needs to be analyzed.

Generally, cyclin D1 expression is thought to be associated with cell cycle progression and cell proliferation. Of note, the cell numbers of S9-3 in the S-phase increased, but there was no difference in cell proliferation activity compared with that of RPMI8226 and Vector. Furthermore, the cell numbers of S9-3 in $\mathrm{G}_{0} / \mathrm{G}_{1}$ - and $\mathrm{G}_{2} / \mathrm{M}$-phases decreased. Therefore, ectopic cyclin D1 overexpression in RPMI8226 could prolong the duration of the S-phase, but not promote the transition of cells to the $\mathrm{G}_{2} / \mathrm{M}$-phase. If prolonging the S-phase duration induced spontaneous fragility, apoptotic cells should be detected in pre- $\mathrm{G}_{0} / \mathrm{G}_{1}$ by cell cycle analysis, and in sub- $\mathrm{G}_{0} / \mathrm{G}_{1}$ by BrdU labelling, or we could not have established a stable cell line with cyclin D1 overexpression. Studies have reported 
that ectopic cyclin D1-induced apoptosis $(29,30)$ was detected in the cyclin D1-inducible system, and they thought that the critical point was the hyperphosphorylation of $\mathrm{Rb}$, because it would in turn release free E2F-1 and induce apoptosis. However, whether a high level of free E2F-1 would cooperate with p53 is still controversial (31-34). In our cyclin D1 transfectant (S9-3), it is of note that we found an increase in the hyperphosphorylated form of $\mathrm{Rb}(\mathrm{ppRb})$, and there were no changes in either p53 or phosphorylated p53 expression. Furthermore, the expression of representative proapoptotic proteins, Bim, Bax, and Bad, or anti-apoptotic proteins, Mcl-1 and $\mathrm{Bcl}-2$, did not change. The decreased expression of $\mathrm{p} 27$ might be due to degradation during progression from the $\mathrm{G}_{1^{-}}$ to S-phase, as reported previously (35). Therefore, we assumed that the increase of ppRb would induce free E2F in S9-3, but the kinds of genes activated by E2F were not elucidated in our study and we did not detect apoptosis induced by cyclin D1 overexpression itself. Accordingly, we state that cyclin D1 overexpression did not increase the number of apoptotic cells in RPMI8226 compared with the parent cell and Vector. Interestingly, we found that $\mathrm{S} 9-3$ seemed to die readily in confluence (data not shown). Therefore, S9-3 might be unstable at low $\mathrm{pH}$ induced by culture cell proliferation, or cell-to-cell contact might induce death signals due to the increase of cell numbers in S-phase.

Next, we investigated the response of S9-3 to treatment by representative anti-myeloma agents. Of note, apoptosis was induced earlier in S9-3 compared with RPMI8226 and Vector. According to the results showing that intrinsic and extrinsic pathways of caspase activation were induced, we expected that the TRAIL signal was activated to induce both pathways. However, we could not detect the suicide phenomenon, in which sTRAIL produced by treatment with anti-myeloma agents induces increased apoptosis in myeloma cells with cyclin D1 overexpression (data not shown).

We have already suggested in our previous study (11) that myeloma cells with cyclin D1 overexpression could be a subpopulation in BM because we thought that myeloma cells could be heterogeneous. Two-thirds of MM patients and normal plasma cells showed expressions of cyclin D2 and D3 with or without trivial cyclin D1 expression in our RQ-PCR analysis (data not shown), and typical MM patients with the translocation of $\mathrm{t}(11 ; 14)(\mathrm{q} 13 ; \mathrm{q} 32)$ did not show expression of cyclin D2, as indicated in cases 2 and 4 in Fig. 3, or cases 15 and 19 in Table I. Therefore, the intensity of cyclin D1 expression in each MM patient could depend on the percentage of myeloma cells with cyclin D1 overexpression in BM. In fact, even in MM patients with $\mathrm{t}(11 ; 14)(\mathrm{q} 13 ; \mathrm{q} 32)$, no plasma cells expressed cyclin D1 by IHC (data not shown). We assume that this is why our results using RPMI8226 derivatives were not consistent with our clinical analysis.

In conclusion, we established a cyclin D1 transfectant in myeloma cells, and this transfectant showed high cell numbers in the S-phase without increased cell proliferation; therefore, the duration of the S-phase was prolonged. This cyclin D1 transfectant also showed high sensitivity to representative anti-myeloma agents by intrinsic and extrinsic pathways of caspase activation. High expression of cyclin D1 could be a favorable prognostic marker in some groups of MM patients; on the other hand, it could induce the instability of genes in myeloma cells, and these myeloma cells could progress to advanced myeloma, in which cyclin D1 overexpression would not be a favorable marker. We suggest that the induction of genomic instability by cyclin D1 expression could be consistent with $\mathrm{t}(11 ; 14)$ translocation and trisomy of chromosome 11 as early events in myeloma cells.

\section{Acknowledgements}

We especially appreciate contributions to the statistical analysis of this work by Kaname Yamamoto (Chugai Pharmaceutical Co., Ltd.). We also appreciate the help of H. Sumida, K. Yamamoto, S. Fukumoto, and R. Matsumoto for their excellent technical or secretarial assistance. This study was supported by the International Myeloma Foundation (The Award in Aki's Memory) in 2007.

\section{References}

1. Lovec H, Grzeschiczek A, Kowalski MB and Möröy T: Cyclin D1/bcl-1 cooperates with myc genes in the generation of B-cell lymphoma in transgenic mice. EMBO J 13: 3487-3495, 1994.

2. Fonseca R, Barlogie B, Bataille R, Bastard C, Bergsagel PL, Chesi M, Davies FE, Drach J, Greipp PR, Kirsch IR, Kuehl WM, Hernandez JM, Minvielle S, Pilarski LM, Shaughnessy JD, Stewart AK and Avet-Loiseau H: Genetics and cytogenetics of multiple myeloma: a workshop report. Cancer Res 64: 1546-1558, 2004.

3. Specht K, Haralambieva E, Bink K, Kremer M, Mandl-Weber S, Koch I, Tomer R, Hofler H, Schuuring E, Kluin PM, Fend F and Quintanilla-Martinez L: Different mechanisms of cyclin D1 overexpression in multiple myeloma revealed by fluorescence in situ hybridization and quantitative analysis of mRNA levels. Blood 104: 1120-1126, 2004

4. Agnelli L, Bicciato S, Mattioli M, Fabris S, Intini D, Verdelli D, Baldini L, Morabito F, Callea V, Lombardi L and Neri A: Molecular classification of multiple myeloma: a distinct transcriptional profile characterizes patients expressing CCND1 and negative for 14q32 translocations. J Clin Oncol 23: 7296-7306, 2005.

5. Bergsagel PL, Kuehl WM, Zhan F, Sawyer J, Barlogie B and Shaughnessy JD: Cyclin D dysregulation: an early and unifying pathogenic event in multiple myeloma. Blood 106: 296-303, 2005.

6. Lesage D, Troussard X and Sola B: The enigmatic role of cyclin D1 in multiple myeloma. Int J Cancer 115: 171-176, 2005.

7. Moreau P, Facon T, Leleu X, Morineau N, Huyghe P, Harousseau JL, Bataille R and Avet-Loiseau H: Recurrent 14q32 translocations determine the prognosis of multiple myeloma, especially in patients receiving intensive chemotherapy. Blood 100: 1579-1583, 2002.

8. Fonseca R, Blood EA, Oken MM, Kyle RA, Dewald GW, Bailey RJ, van Wier SA, Henderson KJ, Hoyer JD, Harrington D, Kay NE, van Ness B and Greipp PR: Myeloma and the $t(11 ; 14)$ (q13;q32); evidence for a biologically defined unique subset of patients. Blood 99: 3735-3741, 2002.

9. Soverini S, Cavo M, Cellini C, Terragna C, Zamagni E, Ruggeri D, Testoni N, Tosi P, De Vivo A, Amabile M, Grafone T, Ottaviani E, Giannini B, Cangini D, Bonifazi F, Neri A, Fabris S, Tura S, Baccarani $\mathrm{M}$ and Martinelli G: Cyclin D1 overexpression is a favorable prognostic variable for newly diagnosed multiple myeloma patients treated with high-dose chemotherapy and single or double autologous transplantation. Blood 102: 1588-1594, 2003.

10. Zhan F, Huang Y, Colla S, Stewart JP, Hanamura I, Gupta S, Epstein J, Yaccoby S, Sawyer J, Burington B, Anaissie E, Hollmig K, Pineda-Roman M, Tricot G, van Rhee F, Walker R, Zangari M, Crowley J, Barlogie B and Shaughnessy JD: The molecular classification of multiple myeloma. Blood 108: 2020-2028, 2006.

11. Katayama Y, Sakai A, Oue N, Asaoku H, Otsuki T, Shiomomura T, Masuda R, Hino N, Takimoto Y, Imanaka F, Yasui W and Kimura A: A possible role for the loss of CD27CD70 interaction in myelomagenesis. Br J Haematol 120: 223-234, 2003. 
12. Jeon HJ, Kim CW, Yoshino T and Akagi T: Establishment and characterization of a mantle cell lymphoma cell line. $\mathrm{Br} \mathrm{J}$ Haematol 102: 1323-1326, 1998.

13. Gabrea A, Bergsagel PL, Chesi M, Shou Y and Kuehl WM: Insertion of excised IgH switch sequences causes overexpression of cyclin D1 in a myeloma tumor cell. Mol Cell 3: 119-123, 1999.

14. Resnitzky D, Gossen M, Bujard H and Reed SI: Acceleration of the G1/S phase transition by expression of cyclins D1 and E with an inducible system. Mol Cell Biol 14: 1669-1679, 1994.

15. Sakai A, Marti GE, Caporaso N, Pittaluga S, Touchman JW, Fend $\mathrm{F}$ and Raffeld M: Analysis of expressed immunoglobulin heavy chain genes in familial B-CLL. Blood 95: 1413-1419, 2000 .

16. Katayama Y, Sakai A, Okikawa Y, Oue N, Asaoku H, Sasaki A, Imanaka F, Tsujimoto $\mathrm{T}$, Takimoto $\mathrm{Y}$, Masuda R, Nakaju N, Otsuki T, Yasui W and Kimura A: Cyclin D1 overexpression is not a specific grouping marker, but may collaborate with CDC37 in myeloma cells. Int J Oncol 25: 379-395, 2004.

17. Uchimaru K, Taniguchi T, Yoshikawa M, Asano S, Arnold A, Fujita T and Motokura T: Detection of cyclin D1 (bcl-1, PRAD1) overexpression by a simple competitive reverse transcriptionpolymerase chain reaction assay in $\mathrm{t}(11 ; 14)(\mathrm{q} 13 ; \mathrm{q} 32)$-bearing B-cell malignancies and/or mantle cell lymphoma. Blood 89: 965-974, 1997.

18. Ishiyama M, Tominaga H, Shiga M, Sasamoto K, Ohkura Y and Ueno K: A combined assay of cell viability and in vitro cytotoxicity with a highly water-soluble tetrazolium salt, neutral red and crystal violet. Biol Pharm Bull 19: 1518-1520, 1996.

19. Durie BG and Salmon SE: A clinical staging system for multiple myeloma. Correlation of measured myeloma cell mass with presenting clinical features, response to treatment, and survival. Cancer 36: 842-854, 1975.

20. Durie BG, Harousseau JL, Miguel JS, Bladé J, Barlogie B Anderson K, Gertz M, Dimopoulos M, Westin J, Sonneveld P, Ludwig H, Gahrton G, Beksac M, Crowley J, Belch A, Boccadaro M, Cavo M, Turesson I, Joshua D, Vesole D, Kyle R, Alexanian R, Tricot G, Attal M, Merlini G, Powles R, Richardson P, Shimizu K, Tosi P, Morgan G and Rajkumar SV: International Myeloma Working Group: international uniform response criteria for multiple myeloma. Leukemia 20: 1467-1473, 2006.

21. Murray AW: Recycling the cell cycle: cyclins revisited. Cell 116: 221-234, 2004.

22. Massagué J: G1 cell-cycle control and cancer. Nature 432: 298-306, 2004

23. Juge-Morineau N, Harousseau JL, Amiot M and Bataille R: The retinoblastoma susceptibility gene RB-1 in multiple myeloma. Leuk Lymphoma 24: 229-237, 1997.
24. Jourdan M, Veyrune JL, De Vos J, Redal N, Couderc G and Klein B: A major role for Mcl-1 antiapoptotic protein in the IL-6induced survival of human myeloma cells. Oncogene 22: 2950-2959, 2003

25. Le Gouill S, Podar K, Amiot M, Hideshima T, Chauhan D, Ishitsuka K, Kumar S, Raje N, Richardson PG, Harousseau JL and Anderson KC: VEGF induces Mcl-1 up-regulation and protects multiple myeloma cells against apoptosis. Blood 104: 2886-2892, 2004.

26. Gomez-Bougie P, Oliver L, Le Gouill S, Bataille R and Amiot M: Melphalan-induced apoptosis in multiple myeloma cells is associated with a cleavage of Mcl-1 and Bim and a decrease in the Mcl-1/Bim complex. Oncogene 24: 8076-8079, 2005.

27. Ishii Y, Pirkmaier A, Alvarez JV, Frank DA, Keselman I, Logothetis D, Mandeli J, O'Connell MJ, Waxman S and Germain D: Cyclin D1 overexpression and response to bortezomib treatment in a breast cancer model. J Natl Cancer Inst 98: 1238-1247, 2006.

28. Sola B and Troussard X: Relevance of cyclin D1 level in the pathogenesis of multiple myeloma. Blood 102: 4245-4246, 2003.

29. Sofer-Levi Y and Resnitzky D: Apoptosis induced by ectopic expression of cyclin D1 but not cyclin E. Oncogene 13: 2431-2437, 1996.

30. Duquesne F, Florent M, Roué G, Troussard X and Sola B Ectopic expression of cyclin D1 impairs the proliferation and enhances the apoptosis of a murine lymphoid cell line. Cell Death Differ 8: 51-62, 2001.

31. Kowalik TF, De Gregori J, Leone G, Jakoi L and Nevins JR: E2F1-specific induction of apoptosis and p53 accumulation, which is blocked by Mdm2. Cell Growth Differ 9: 113-118, 1998.

32. Bates S, Phillips AC, Clark PA, Stott F, Peters G, Ludwig RL and Vousden KH: p14ARF links the tumor suppressors RB and p53. Nature 395: 124-125, 1998.

33. Holmberg C, Helin K, Sehested M and Karlström O: E2F-1induced p53-independent apoptosis in transgenic mice. Oncogene 17: 143-155, 1998.

34. Phillips AC, Ernst MK, Bates S, Rice NR and Vousden KH: E2F-1 potentiates cell death by blocking antiapoptotic signaling pathways. Mol Cell 4: 771-781, 1999.

35. Shirane M, Harumiya Y, Ishida N, Hirai A, Miyamoto C, Hatakeyama S, Nakayama K and Kitagawa M: Down-regulation of p27 (Kip1) by two mechanisms, ubiquitin-mediated degradation and proteolytic processing. J Biol Chem 274: 13866-13893, 1999. 